\title{
A Report from an Online Course on Global Disruption and Information Technology
}

\author{
Bill Tomlinson \\ Department of Informatics \\ Bren School of ICS \\ University of California, Irvine \\ wmt@uci.edu
}

\author{
Donald J. Patterson \\ Department of Computer Science \\ Westmont College \\ dpatterson@westmont.edu
}

\author{
Bonnie Nardi \\ Department of Informatics \\ Bren School of ICS \\ University of California, Irvine \\ nardi@uci.edu
}

\begin{abstract}
"Computing Within Limits" represents a new paradigm in thinking about computing. To help communicate this new perspective to a broader audience, we created, taught, and are continuing to teach a multi-campus online course through the University of California (UC) titled "Global Disruption and Information Technology." This article presents a report on our experiences designing this course and delivering the first two offerings to several hundred UC undergraduates. We discuss the history and motivation for the course; specific details of the course content; the technological platforms used in delivering the course; the student population; and the student experience taking the course. We hope that this paper, detailing our efforts at "teaching LIMITS," will help others interested in offering similar courses take advantage of our experiences and help more students become engaged with this critical set of issues.
\end{abstract}

\section{CCS Concepts}

Social and professional topics $\rightarrow$ Professional topics $\rightarrow$ Computing education $\rightarrow$ Computing education programs $\rightarrow$ Information science education - Applied computing $\rightarrow$ Education $\rightarrow$ Distance learning

\section{Keywords}

Computing within limits; Limits; Sustainability; Education; Online learning.

\section{BACKGROUND}

In 2014, the authors of this paper proposed an undergraduate course to the UC system motivated by the perspectives, concerns, and knowledge fundamental to the Computing Within Limits community. Through a competitive process, the University of California Office of the President's (UCOP) Innovative Learning Technologies Initiative (ILTI) awarded us a grant to prototype and run the course. Our goal was to enable students to learn a range of concepts-about information technology, global sustainability, and various limiting factors on industrial civilization-that are foundational to the thinking that underlies the LIMITS

Permission to make digital or hard copies of all or part of this work for personal or classroom use is granted without fee provided that copies are not made or distributed for profit or commercial advantage and that copies bear this notice and the full citation on the first page. Copyrights for components of this work owned by others than the author(s) must be honored. Abstracting with credit is permitted. To copy otherwise, or republish, to post on servers or to redistribute to lists, requires prior specific permission and/or a fee. Request permissions from Permissions@acm.org.

LIMITS '16, June 08 - 10, 2016, Irvine, CA, USA

Copyright is held by the owner/author(s). Publication rights licensed to ACM. ACM 978-1-4503-4260-5/16/06$15.00

DOI: http://dx.doi.org/10.1145/2926676.2926689 perspective. UCOP's goal was primarily to respond to California Governor Brown's initiative to explore online teaching as a potential source of increased efficiency in higher education [16]. The course, titled "ICS 5: Global Disruption and Information Technology," met with some success as UCI awarded it the 2015 Celebration of Teaching Instructional Technology Innovation Award.

ICS 5 was part of one of the first set of online courses to be offered across the nine undergraduate campuses of the University of California system. The course has been offered twice to date: first in Winter 2015, and then again in Fall 2015. As of this writing it is currently being offered a third time in Spring 2016. Teaching a course across nine different campuses has been no small undertaking because, despite the common name, the separate UC campuses have largely independent administration and course requirements.

One of our strategies for gaining exposure across different campuses was to qualify ICS 5 as a "General Education" (GE) requirement. GE courses form a portfolio of options from which undergraduates can select to meet a breadth requirement. Due to constant student demand for courses that satisfy various GE requirements, having ICS 5 satisfy the "Science and Technology" GE requirement at UC Irvine allowed the course to attract hundreds of students from dozens of majors to enroll in the online ICS 5 course over its first two offerings. The third offering, currently underway, has our largest enrollment at 217 students.

\section{RELATION TO PREVIOUS EFFORTS}

The role of sustainability in computing education has been a growing topic of interest to the computing community (e.g., [6]). Sterling [15] argues that "sustainability does not simply require an 'add-on' to existing structures and curricula, but implies a change of fundamental epistemology in our culture and hence also in our educational thinking and practice." (p. 50) Teaching LIMITS involves embracing the notion of fundamentally rethinking certain tenets of industrial civilization.

A course at $\mathrm{KTH}$, addressing a range of topics at the juncture of IT, sustainability, and related topics $[3,12]$, is perhaps the most similar existing course to ICS 5. In [12], the instructors offer a framework through which to conceptualize courses in this domain based. The KTH course, designed for graduate students, was targeted at a more experienced student community than the undergraduates enrolled in ICS 5. One of the challenges we faced was that most of our students took the course to satisfy a Science and Technology GE requirement, and typically were not science or technology majors. We see our work on ICS 5 as complementary to Pargman and Eriksson's course, at a more introductory level. 


\section{PEDAGOGICAL CONTENT}

The course syllabus included the following summary of the course:

The world is changing rapidly. Environmental concerns, social transformations, and economic uncertainties are pervasive. However, certain human needs remain relatively constant- things like nutritious food, clean water, secure shelter, and close human social contact. This course seeks to understand how sociotechnical systems (that is, collections of people and information technologies) may support a transition to a sustainable civilization that allows for human needs and wants to be met in the face of global change.

In this course, students will learn about how technology works, and how humans and technology interact. In order to explore these relationships, students will be asked to interrogate what is important to them in life, and how technologies can support those aspects of their lives. Unlike many online courses, this course seeks to include interactive components designed to support collaboration among students, faculty, and teaching staff, thus allowing students to be part of an engaged community of scholars and learners.

Topics covered will include: introductions to the science behind global change, scientific studies of human wellbeing, and a range of topical discussions such as IT for local food production, computational systems to support resource sharing, resilient currency technologies, and localized, low-energy technological infrastructure.

There were three primary curricular goals for this course. The first was to educate students about the science of global change. The second was to educate students about the sociotechnical approach to technology design, which the three instructors have pursued throughout their careers. The third was to engage students in understanding and critiquing their own values and the processes by which such values may be brought to bear in the creation of sociotechnical solutions to global change.

In each week of this course, we typically offered several short (515 minute) videos, as well as several readings. A number of papers from LIMITS 2015 were included in the second offering of the course, replacing a book, Green Illusions [20], which we had asked students to read in the first offering.

One of the challenges of teaching and responding to sustainability concerns in general, and those in this course in particular, is to avoid a sense of despair or hopelessness in the presentation. The problems are overwhelming, but we felt that creating some enthusiasm for tackling them and helpful ways of thinking about them was an important point of offering the course. As a result, we structured the course as a "descent" into the problems in the early weeks, and then an "ascent" to solutions, ideas for solutions, and case studies of successes in the later weeks.

The course followed weekly themes with additional course time spent on administrative concerns such as feedback to instructors. (Note this set of topics is from the second offering of the course, but is very similar to the first offering, except for the addition of the LIMITS papers. Readings are examples, rather than a comprehensive listing. The third offering has preserved this structure.)
- Foundations of Global Disruption, Well-being and IT

Basic frameworks on where the idea of global disruption comes from, who the authoritative sources in the space are and the theoretical framings that we start from in addressing these problems.

- Intergovernmental Panel on Climate Change (IPCC)

- National Academies, Computing Research for Sustainability [7]

- Life Cycle Analysis

- Maslow/Max-Neef

- Peak Week

Recognition of the reality of limited resources and the impact of both using those resources and exhausting those resources and the interconnection between the different resources that are peaking.

○ Peak oil/energy

- Sociotechnical systems

○ "Preliminary thoughts on a taxonomy of value for sustainable computing" from LIMITS 2015 [19]

- Collapse Informatics [18]

\section{- Disruption Week}

Ways in which disruption is currently happening globally and the ways in which previous disruptions have occurred, sometimes with negative outcomes, "collapse" and sometimes with positive outcomes from "survival" to "resilience".

○ "The Collapse of Complex Societies" [17]

○ "Haitian Resiliency" [13]

- Case Study of urban agriculture in Cuba $[1,2]$

- Wicked Week

In this week we acknowledge how complex and difficult sustainability challenges are from the psychology burden they put on individuals to the unintended consequences of seemingly sustainable choices.

- "Deviant and Guilt-ridden" from LIMITS 2015 [5]

○ Jevons Paradox/rebound effect

$\circ \quad$ Greenwashing

- Happy Week

In this we begin to turn things around and focus on the positive possibilities for change, both in alternative framings for how "growth" could be interpreted and how different imaginations of the future don't necessitate apocalyptic outcomes.

- Universal Declaration of Human Rights

- Transition Towns

- Quality of life

- "Foster the "mores', counter the "limits" from LIMITS 2015 [4]

- $\quad$ Food and Community Week

An exploration of the various ways that information technologies can engage productively and sustainably with the provision of human nutrition and community building.

- George Monbiot [8]

$\circ \quad$ Local food needs 


\section{○ Urban farming \\ ○ Aquaponics}

- Economy Week

A look at the economic aspects of global disruption, and how IT-based economic innovations could effect change in this space.

○ "Inequality and LIMITS" from LIMITS 2015 [9]

- Alternative currencies

○ Capitalism

- $\quad$ Alt Week

Offers an assortment of alternate ways to engage with the domain of computing within limits.

- Alternative networks

Libraries of the future

An internet quine

"Information systems for the age of consequences" [14] and "On the limits of limits" [11] from LIMITS 2015

\section{- Hope Week}

Presents variety of successful projects that communities and governments have taken on that have resulted in meaningful positive changes in quality of life, environmental health and individual happiness.
$\circ \quad$ Air quality
- Fish restoration
- Ozone depletion

In addition to readings and in an effort to engage students in as many ways as possible, we occasionally took them on virtual field trips - videos we shot on location at venues such as UCI's eWaste recycling center, an aquaponics facility near UC Santa Cruz, and an urban garden in Los Angeles. In addition, we had numerous video guest lectures with scholars from around the world who we solicited specifically for this course. In one case we were able to bring Professor Joseph Tainter to give an in-person colloquium, meet faculty over the course of the visit, and then film an interview at UC Irvine. In other cases, we found opportunities when the scholars were in the area or when we were in the scholar's area to film interviews.

To further reinforce the activist stance we wanted students to develop, we required each person to undertake a capstone activity for the course. Students were asked to create videos about a topic of interest to them that related to the concepts of the course. In the first offering, these projects were done in teams of approximately four students, working together remotely. Requiring remote group work among undergraduates who, despite their embeddedness in a digitally mediated social world, proved to be much more difficult than expected and required a special attention to the technical tools that we had at our disposal. In the second offering, due to significant negative feedback about the challenges of online group projects, students worked independently on their projects. Student projects (discussed in more depth below) across both offerings covered a wide array of topics from pointed critiques of UCI's sprinkler systems to humorous satires of Apple iPhones.

A key premise of the course is that while technology may be able to address some aspects of sustainability, the core problem lies with the nature of current industrialized society. Many students come to the course with a "solutionist" mindset: technology is good for fixing things and making things better, and therefore the core challenge is to find the right things to fix, and then make some innovative technology to correct the problem. While there are some elements of the course where we point to technological solutions to concrete problems, the broader remit is to help students understand that a problematic cultural perspective lies at the root of many of the issues that industrial civilization faces. Throughout the course, we seek to help students think about these cultural and political issues, and when thinking about using technology to solve problems, focus largely on how IT can help shift sociopolitical perspectives in beneficial ways.

\section{TECHNOLOGY}

The course readings and videos, as well as quizzes, discussion boards, and other materials, were organized and presented to the students via the Canvas learning management system. This system is an outsourced, third party solution competitive with Moodle or Blackboard, but with a distinctly different business model. Canvas is run by a for-profit company, Instructure, whereas Moodle is open-source software. Canvas was chosen by the UC system, and at UCI in particular, due to a perceived need for a single solution to the problem of online learning, and in UCI's case, due to concerns with expanding the homegrown course management system (the Electronic Education Environment (EEE)) to meet the needs of online courses. The students in ICS 5 appeared to have a largely positive experience with Canvas. However, while the students were apparently insulated from it, the teaching staff developed a deep dissatisfaction with Canvas over the process of creating and offering this course.

Despite misgivings about Canvas, the campus's formal adoption of the system caused it to be again used in the second offering of the course, but this time it was integrated into UC Irvine's infrastructure rather than the UC Office of the President's, as was the case in the first offering. We had access to an Instructional Support Specialist at UCI who was able to help us work around some of the ongoing issues. However, many of the problems persisted in this offering as well (and into the third offering).

As much as possible, we attempted to use the best online tool for a given task in order to provide the best experience possible for our students. We used Canvas as a kind of directory or schedule for linking a variety of different tools together. We used YouTube and Vimeo to host videos because they supported resilient, lowbandwidth connections. We used LiveChat to host real-time communication (see Discussion).

While as instructors we were careful to choose online tools whose affordances matched the task at hand, when the students undertook group work they tended to select tools they were familiar with, often with frustrating results. For example students used text messaging, Facebook groups, Dropbox, Snapchat, and Twitter to communicate for the group project. While effective for social media, a common complaint was ensuring accountability of message receipt and response amongst the entire group.

\section{STUDENT POPULATION}

In the first offering of the course, we had 95 students. The vast majority were students at UCI, with four students from other campuses. Among the 95 students, were 28 different majors, from Anthropology to Art to Chemical Engineering to Literary Journalism. Only 24 students were from IT-based majors (computer science, informatics, software engineering), reflecting the impact of the course satisfying the "Science and Technology" GE requirement, which is met by a number of required courses for the various IT majors. In the second offering, we had 149 
students, a $56 \%$ increase, all but one from UCI, across 38 majors, with only 19 from IT-based majors. As of this writing, 217 students have registered for the third offering of the course (see Figure 1).

This diversity of students, and the fact that many of them did not have technical backgrounds, made it critical for us to teach the course in ways that would be accessible to students without technical experience. We tried to leverage the diversity of the student body to enrich the course, encouraging students to draw on their personal experiences and expertise from their majors when replying to discussion boards and creating their final projects.

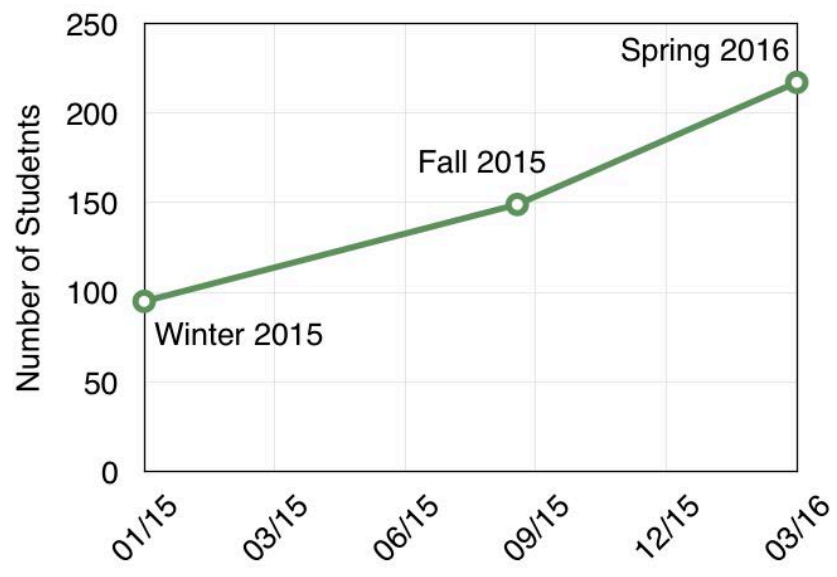

Figure 1: Enrollment over time

\section{STUDENT EXPERIENCE}

Students appeared to develop a more thoughtful understanding of sustainability and related issues over the 10 weeks of the course. While we have not done a rigorous qualitative or quantitative analysis of student discussion responses, anecdotally, we found improvement in depth of engagement with the course topics between the beginning and end of the course. For example, a Week 1 assignment asking students to write a paragraph describing their background and interests produced numerous responses focusing on sports, computer games, and the general education requirement. In a Week 10 discussion, though, where we required students to ask a question of the teaching staff and their peers, students usually focused their questions on topics such as carbon dioxide, water, greenwashing, fossil fuels, and other topics central to the content of the course. We recognize that this shift across the 10 weeks was likely influenced by the fact that most of the students had little idea what to expect from the course at the beginning, and, over time, got used to discussing the course topics.

Student evaluations completed at the end of the course were generally positive, with the course receiving averages of 8.04 for the first offering and 7.34 for the second offering, on a 1-9 scale.

UCI course evaluations do not include questions tailored to capturing the broad intellectual impact of the course. While KTH appears to have a question in which students rated how "meaningful" a course was for them [3], UCI's evaluations ask free-response questions about: instructor's teaching strengths, areas for improvement, and other comments, and numeric questions about instructor enthusiasm, stimulating interest, meeting objectives, instructor accessibility, fairness, encouraging students to think, clarity, role of assignments and exams, and overall evaluations of the instructor and the course. The sheer existence of a question about how meaningful a course has been demonstrates a commitment to a particular kind of educational outcome, and one that is more aligned with sustainability in general. Nevertheless, in terms of "encouraging students to think," which is perhaps closest to being meaningful, the course scored an $8.40 / 9$ and $8.01 / 9$ in the two offerings of the ICS 5 to date, indicating that it was effective at encouraging students to think.

Most of the students' free response comments focused on the instructor (as requested in the first two questions), and on the logistics of the course. However, a few comments spoke to what we hoped the student experience would be.

\section{Student A: I really liked this course, it was challenging in the sense that it made me think about my own personal life compared to a course that made me think hard on the subject at hand.}

Student B: I like it when he takes us on field trips virtually like the time when he took us to the aquaponic farm with his family and I found that fascinating! It was very informative and it was nice seeing the place from inside rather than showing pictures on a powerpoint.

Student C: This course has really opened my eyes about issues I had never thought about.

Interestingly, there were relatively few comments of this kind in the final evaluations, compared to the large number of logisticsrelated comments (both positive, for example regarding their liking of the online nature of the course, and negative, pertaining to the abundance of reading). It is not clear if that indicates a lack of desired impact, or a student understanding that the evaluation forms are primarily intended to be ways to offer compliments and complaints about particular details rather than to comment on the overall impact of the course.

However, measuring impact is tricky, and does not always boil down to averages. In an email exchange after the course was over, one of the students in the second offering wrote to the instructor, "I think you'd be happy to know that I'm working at $<$ a global environmental information company>. How I ended up here was largely inspired by what I took away from ICS 5."

\section{STUDENT PROJECTS}

One lens through which we were able to gain insight into the thinking and approaches that the students brought to the class was by analyzing the final projects that they submitted. In the first offering of the course each student was required to participate in a final group project that consisted of a short research paper and a video presentation. The 95 students submitted 25 papers, which were quite diverse in their subject matter.

We categorized the projects into hierarchical categories as shown in Figure 2. The high-level categories included Food, Water, Transportation, Economics, and Generic. The "Generic" category referred to papers that made non-specific appeals to sustainability in general ("We need a way to bring energy-awareness to the masses") and reflected the ability of the student authors to mimic the dominant narratives in sustainability or repeat research findings that they had read, while stopping short of critical engagement with the results or actual innovation. Fortunately this category was only a small proportion of the papers.

Another common theme is personal experience, which was elicited from students by requiring them to tie their project to one or more UC campuses. Many of the projects focused on critiques 
of campus sustainability efforts or new opportunities for such efforts. Several evaluated a campus bike-sharing program that has seen limited use, offered proposals for supporting carpooling (to/from campus), and for improving the campus bus system, and tracking food waste in the dining halls. Although the solutions and ideas have been largely prototyped in other venues, these papers were more encouraging as they showed the students beginning to evaluate and take ownership for sustainability in their own community.

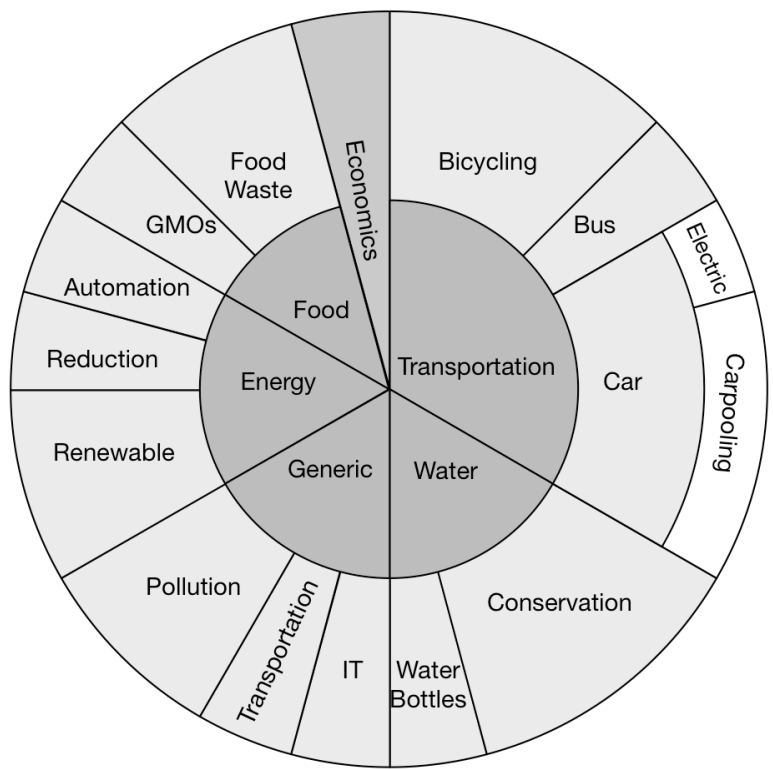

Figure 2: Final project foci

The groups that discussed water, a particularly relevant problem in California, had difficulty thinking beyond their personal experience despite the very clear statewide messages they were getting from various public education channels (billboards, utility bills, stickers on campus water fixtures). Most discussion was about the water bottle refilling stations, landscape watering on campus and household usage. The students didn't get as far in their thinking as to consider the amount of water used by agriculture, or other local industries, which consume more and are considerably harder to reduce.

One example of how complex the LIMITS paradigm can be to teach was reflected in the specifics of one of the projects that a team submitted, but for privacy reasons we can only discuss in general terms. In this project the students took a position that was not well-aligned with conventional understandings of sustainability. This was a concern, but we were open to hearing the explanation for the countervailing view point. The students were surprised to discover in their research that the University was doing exactly what they supported in order to save money. The student's argument then hinged on a definition of "sustainability" that wasn't correct for our context. They were arguing that the University of California would be more "sustainable" as an institution by taking the exact opposite kind of action that we were advocating and therefore saving money. Of course, they were right. But the students did not ask why the costs were lower, how long that could continue or what the exogenous costs might be. Somewhere between the various ways of understanding sustainability and their own very immediate financial interests the students missed the forest for the trees.
One group produced what we thought was a novel idea at the intersection of IT and sustainability, arguing for an expansion of reverse vending machines. These machines accept goods for recycling and pay money back on the spot. Machines like this for recycling cans and bottles and phones exist around campus, but are plagued by maintenance problems. The students suggested addressing existing problems and considering a textbook return machine. While still embedded in the culture of a U.S. undergraduate student, we felt the idea interestingly joined automation, economics, sustainability, and campus culture in a fresh, provocative way.

\section{DISCUSSION}

While teaching the course, we found that many students struggled to grasp the core premise of LIMITS. This premise runs counter to prevailing mental models that most residents in industrialized civilizations adhere to, e.g., that growth is inherently good, that technology can and should support that growth, and that more technology, is, on balance, better. Throughout the course, we implicitly and explicitly looked for ways to overcome students' barriers to entry into LIMITS ways of thinking. The core content of the course, in particular the effort to shed positive light on various LIMITS topics and the inclusion of LIMITS papers, was the most central of these efforts. Having the course online and satisfying GE requirements, encouraged students to enroll in a course that they might otherwise not have included in their coursework. Incorporating interesting field trips and guest lectures and enabling students to create engaging, personally relevant final projects also served to help students become engaged with the content of the course.

One of the difficulties of teaching purely online courses is creating meaningful student contact. In the initial offering of the course, when the material was being developed, the teaching staff consisted of three faculty and two TAs. In this configuration we arranged the class into discussion groups so that over the span of the course, discussions would occur among the same smallish groups of about 20 people. This was done to improve the experience and build a common experience among a manageable subset of the students. In the second offering, we had one professor and two TAs for a larger number of students.

The lack of frequent, direct, student contact made it a bit more challenging to steer in-class discussions toward relevant topics. We needed to do much more planning in advance, rather than spontaneously responding to students' comments. Nevertheless, throughout the course, we sought to use technology to support our efforts to engage students dynamically.

For example, during the first offering we experimented with rapid communication by using software that is traditionally used for call center management. LiveChat was a networked software service that placed a chat box on the course web page and connected it to the faculty's laptop computers. When a student communicated via the course website, the comment or question was distributed in a round robin fashion to the faculty who were online at a given moment and could respond synchronously. If no faculty was online a ticket was opened in a feedback workflow. Faculty were emailed about the ticket and could engage asynchronously with the initiating student. Although potentially a time burden, in practice this system communicated a concern for responsiveness to the student that was very well received. The vast majority of comments were simple clarification concerns and rarely took more than a moment to resolve. The perception of the students that a faculty member was available at a moment's notice 24 
hours a day, was quite impressive. However, the overhead of finding funding to pay for this system caused it not to be used in the second offering. In the third offering we are experimenting with Skype chat but it's too soon to say how it will work.

In the first offering's asynchronous discussion boards, because there were three of us, we were able to regularly participate in the online discussions required for the class. Both of these types of participation, however, became difficult in subsequent offerings of the class when enrollment increased and there was only one faculty member. This was the case when Professor Tomlinson taught the second offering of the class in the Fall Quarter of 2015 with an enrollment of 149, and currently when Professor Nardi is teaching the third offering of the course in the Spring Quarter of 2016 with an enrollment of 217 . On the one hand we are delighted to have high and growing enrollment, but the relationship between student and professor has necessarily become more impoverished.

Beyond the context of teaching LIMITS online, many of our discussion points and lessons learned translate to implications for online collaboration generally, especially academic collaboration. While there are aspects of meeting face-to-face that are extremely effective and powerful [10], transportation takes time and significant resources to accomplish. As participants increase, so does the consumption of resources. Other less visible professions than higher education are also experimenting with online collaboration with similar mixed results; the National Science Foundation gave up on virtual meetings because there were so many complaints. But there is hope-NSF panelists with experience in virtual worlds and virtual games preferred the virtual meetings held in 3D worlds with avatars, especially those for whom traveling to DC was a major trip.

Ironically, while we had a virtual classroom available to us during the first offering of the course, it was overbooked and unavailable for most of the duration of the class. Even had such a space been available, not many students or professionals currently have experience in virtual worlds. Successful future collaboration will likely require an intentional consideration for how to socialize participants to work effectively in virtual contexts.

\section{CONCLUSION}

This paper reports on our experiences creating and offering a course to help University of California undergraduates learn about computing within limits. This set of topics is critically important to the future of the computing discipline, and potentially a powerful transformative force in the world more broadly. Enabling more people to become engaged with these topics can help it have greater impact. We see teaching LIMITS in general, and this online course in particular, as a pathway to this greater engagement.

With more than 186,000 undergraduates drawn from the world's best and brightest students, the University of California is an important global institution of higher learning. It is the largest and most highly ranked system of public higher education in the world. Enabling as many UC undergraduates as possible to take this course could help LIMITS establish itself more firmly in the public understanding of computing. We hope it is a model and inspiration for other efforts at universities around the world. We believe this paper can make a small contribution to this greater effort.

\section{ACKNOWLEDGMENTS}

This material is based in part on work supported by the NSF under Grants No. IIS-1421498 and CCF-1442749. We want to acknowledge Juliet Norton, who created the first framework for the online course, as well as the TAs from our first offering, Marcel Pufal and Aubrey Slaughter, whose contributions to the development of the course were integral to the work that we have presented. We would also like to thank Ellen Osmundson, André van der Hoek, Hal Stern, Sarah Eichhorn, Caryn Neiswender, Briandy Walden, Rebecca Black, Ankita Raturi, Clara Marquez Caldeira, and Anju Prakash for their efforts in bringing various stages of the course into existence.

\section{REFERENCES}

[1] M. Chan and E. Roach. 2013. Unfinished Puzzle: Cuban Agriculture: The Challenges, Lessons \& Opportunities. Food First Books/Institute for Food and Development Policy.

[2] C. Clouse. 2014. Farming Cuba: Urban Agriculture From the Ground Up. Princeton Architectural Press.

[3] Eriksson, E. and Pargman, D. 2014. ICT4S Reaching Out: Making sustainability relevant in higher education, in ICT for Sustainability 2014 (ICT4S-14). Atlantis Press.

[4] X. Gui and B. Nardi. 2015. Foster the "mores", counter the "limits". First Monday, 20(8).

[5] B. Knowles and E. Eriksson. 2015. Deviant and guilt-ridden: Computing within psychological limits. First Monday, 20(8).

[6] S. Mann, L. Smith, and L. Muller. 2008. Computing education for sustainability. SIGCSE Bull. 40, 4 (November 2008), 183-193. DOI=http://dx.doi.org/10.1145/1473195.1473241

[7] L. Millett and D. Estrin (eds). 2012. Computing Research for Sustainability. National Academies Press.

[8] G. Monbiot. 2014. The age of loneliness is killing us. The Guardian.

http://www.theguardian.com/commentisfree/2014/oct/14/age -of-loneliness-killing-us

[9] B. Nardi. 2015. Inequality and limits. First Monday, 20(8).

[10] G. M. Olson and J. S. Olson. 2000. Distance matters. Hum.Comput. Interact., 15(2):139-178.

[11] D. Pargman. 2015. On the limits of limits. First Monday, 20(8).

[12] D. Pargman and E. Eriksson. 2013. "It's not fair!" - making students engage in sustainability. Engineering Education for Sustainable Development (EESD 13).

[13] D. Patterson. 2015. Haitian resiliency: A case study in intermittent infrastructure. First Monday, 20(8).

[14] M. S. Silberman. 2015. Information systems for the age of consequences. First Monday, 20(8).

[15] S. Sterling. 2004. Higher education, sustainability, and the role of systemic learning, in P.B. Corcoran and A.E.J. Wals (Ed.) Higher education and the challenge of sustainability: Problematics, Promise and Practice. Springer: Netherlands. 49-70.

[16] C. Straumsheim. 2014. It Takes Time. Inside Higher Ed. https://www.insidehighered.com/news/2014/08/13/changingeconomy-changes-online-education-priorities-u-california

[17] J. Tainter. 1990. The Collapse of Complex Societies. New Studies in Archaeology. Cambridge University Press.

[18] B. Tomlinson, M. S. Silberman, D. Patterson, Y. Pan, E. Blevis. 2012. Collapse Informatics: Augmenting the 
Sustainability \& ICT4D Discourse in HCI. in ACM Conference on Human Factors in Computing Systems (CHI 2012).

[19] K. Toyama. 2015. Preliminary thoughts on a taxonomy of value for sustainable computing. First Monday, 20(8).
[20] O. Zehner. 2012. Green Illusions: The Dirty Secrets of Clean Energy and the Future of Environmentalism. University of Nebraska Press. 